Research Article

\title{
Poly Lactic-Co-Glycolic Acid- (PLGA-) Loaded Nanoformulation of Cisplatin as a Therapeutic Approach for Breast Cancers
}

\author{
Saad Alkahtani $\left(D,{ }^{1}\right.$ Saud Alarifi, ${ }^{1}$ Gadah Albasher, ${ }^{1}$ Mohammed Al-Zharani, ${ }^{2}$ \\ Nada H. Aljarba, ${ }^{3}$ Mohammed H. Almarzoug, ${ }^{1}$ Norah M. Alhoshani, ${ }^{1}$ Norah S. AL-Johani, \\ Hani Alothaid ${ }^{\mathrm{D}},{ }^{4}$ and Abdullah A. Alkahtane ${ }^{1}$ \\ ${ }^{1}$ Department of Zoology, College of Science, King Saud University, Riyadh, Saudi Arabia \\ ${ }^{2}$ Department of Biology, College of Science, Imam Muhammad Ibn Saud Islamic University, Riyadh-11432, Saudi Arabia \\ ${ }^{3}$ Department of Biology, College of Sciences, Princess Nourah Bint Abdulrahman University, Riyadh, Saudi Arabia \\ ${ }^{4}$ Department of Basic Sciences, Faculty of Applied Medical Sciences, Al-Baha University, Al-Baha-65431, Saudi Arabia \\ Correspondence should be addressed to Saad Alkahtani; salkahtani@ksu.edu.sa
}

Received 19 April 2021; Revised 4 June 2021; Accepted 19 June 2021; Published 29 June 2021

Academic Editor: Hui-Min David Wang

Copyright (C) 2021 Saad Alkahtani et al. This is an open access article distributed under the Creative Commons Attribution License, which permits unrestricted use, distribution, and reproduction in any medium, provided the original work is properly cited.

\begin{abstract}
Despite recent advancements in cisplatin (cis-diamminedichloroplatinum II) and other platinum-based chemotherapeutic drugs for treating solid tumors, their uses are limited by either in terms of toxicity and/or acquired drug resistance. These side effects have a dangerous problem with higher dose for severe patients. To overcome the low therapeutic ratio of the free drug, a polymeric nanoparticle drug delivery system has been explored promoting delivery of cisplatin to tumors. Recently, the applications of nanoparticles (NPs) have been underlined for encouraging the effects of chemotherapeutic drugs in cancerous cells. The intention of this project is to assess the potential of poly lactic-co-glycolic acid (PLGA) nanoparticles (NPs) for enhancing the effects of anticancer drug cisplatin. For the purpose, we have synthesized PLGA-cisplatin nanoparticles for increasing its bioavailability and studied the comparative cytotoxicity of free cisplatin and PLGA-cisplatin against MCF-7 cancer cell lines and HEK-293 normal cell lines. We have also analyzed the hallmarks of PLGA-cisplatin-induced apoptosis. The outcomes of this study may provide the possibility of delivery of anticancer drug to their specific site, which could minimize toxicity and optimize the drug efficacy.
\end{abstract}

\section{Introduction}

Cancer has exceeded cardiovascular and cerebrovascular diseases as the foremost cause of death worldwide [1-3]. Thus, the overload of cancer on healthcare systems consistently increases which requires more investigations to further advance an early and rapid recognition of such deadly disease $[4,5]$. In particular, breast cancer $(\mathrm{BC})$ is the common diagnosed noncutaneous form of solid tumor among women which is related with larger tumor size, higher grade, and frequent nodal immersion and becomes primary cause of death among women [6-8]. Although, the risk of BC consistently increases with different age groups, due to an elevated level of estrogen metabolite which generates reactive oxygen species (ROS) and prompts uncontrolled DNA production [9]. The incidence of $\mathrm{BC}$ is linked to numerous factors, among which the utmost common being its heterogeneous nature [10]. The inter/intratumoral heterogeneity, typically affecting the physical appearance of the breast and molecular variety, shows a pivotal role in its histology and staging [11]. The molecular stratification of $\mathrm{BC}$ is primarily based on the expression of hormonal receptors, namely, the estrogen receptor (ER) and progesterone receptor (PR), along with human epidermal growth factor receptor 2 (HER2) [10, 12, 
13]. Owing to its heterogeneity, the treatment is complicated and the healing methodologies should be taken carefully [13].

In the last few decades, successful invention for cancer therapy is the use of metal-based pharmaceuticals after the serendipitous discovery of cis- $\mathrm{Pt}\left(\mathrm{NH}_{3}\right)_{2} \mathrm{Cl}_{2}$ has been extensively studied and remains a front-line treatment against a variety of solid tumors [14-16]. It was regularly accepted that cisplatin is a model chemotherapeutic drug of high proficiency and induces cytotoxicity by interference of transcription and/or the DNA replication mechanisms [17]. The interaction of the cisplatin drug and DNA forming DNA adducts leads to the activation of numerous signal transduction corridors involved in apoptosis [18]. However, there are certain limitations viz. severe toxicity, intrinsic and extrinsic resistance, and patient compliance $[19,20]$. Additionally, cisplatin retains itself in tumor cell for a short duration due to low molecular weight and it can easily pass into the blood circulation causing damage to normal cells [21]. To conquer such issues, new strategies in the form of combination therapies were employed to improve the drug delivery profile of cisplatin towards the cancer cell line [22, 23]. It provides the possibility of targeted delivery of a certain anticancer drug to the tumor site, which could minimize toxicity and optimize the drug efficacy [24].

To date, various nanocarrier-based delivery systems like liposomes, micelles, and dendrimers have been taken that permit more directed release of the drugs [25-27]. These nanoparticles modify the drug release profile for the purpose of improving drug bioavailability because of their ability for tunable payload release to the specific target domain with minimum toxicity to surrounding healthy tissues. Among numerous biodegradable polymers, poly lactic-co-glycolic acid (PLGA) has been extensively used as drug carriers in clinical medicines as it is an FDA-approved copolymer $[24,28]$. PLGA has a promising degradation characteristic that makes it ideal for sustained release for hydrophilic or hydrophobic drug. Furthermore, they can easily conjugate with specific target molecules and have the potential to alter their surface properties and improve interactions to reach specific tissues or cells [29]. Recently, DomínguezRíos et al. analyzed the significant improvement in the cytotoxicity along with an enhanced internalization of NPs as compared to free cisplatin for HER2 targeted ovarian cancer [30]. Similarly, Moreno et al. evaluated the in vivo efficacy of cisplatin-loaded PLGA nanoparticles administered to tumor-bearing mice, which provide a promising carrier for cisplatin avoiding its side effects without a decline of the efficacy [31].

With this objective to treat breast cancer by utilizing the advantages of PLGA in this study, we chose PLGA nanoparticles as a core for the encapsulation of a cisplatin drug (Figure 1), for the purpose of safe delivery to the targetspecific region. In vitro anticancer efficacy and cellular localization of this formulation were investigated on MCF-7 cancer cell lines. We assumed that delivery of drug would result in enhanced anticancer efficacy by modulating the tumor microenvironment to increase the penetration of PLGA NPs into the tumor cell.

\section{Materials and Methods}

2.1. Chemicals. Poly(D, L-lactide-co-glycolide) (PLGA, Resomer ${ }^{\circledR}$ RG 502 H Mw 7-17 kDa lactide: glycolide 50:50, acid terminated), cisplatin, dimethylformamide (DMF), polyvinyl alcohol (PVA, 9-10 kDa, 80\% hydrolyzed), acetic acid, orthophenylenediamine (OPDA), phosphate buffer saline (PBS), 2-(N-morpholino) ethanesulphonic acid clorhydrate (MES) were purchased from Sigma-Aldrich. Constituents for cell culture media consist of fetal bovine serum (FBS), Dulbecco's modified Eagle medium (DMEM), trypsin, penicillinstreptomycin-neomycin (PSN) antibiotic cocktail, and ethylenediaminetetraacetic acid (EDTA) were procured from Gibco (Grand Island, NY, USA). Antibodies were bought from Santa Cruz Biotechnology, Dallas, Texas, USA, and eBioscience, San Diego, USA. Dyes were acquired from Thermo Fisher Scientific, USA. All other chemicals and solvents (purchased from Sigma-Aldrich) were used as received without further treatment.

2.2. Synthesis of PLGA-Cisplatin NPs. Cisplatin-loaded NPs were obtained by a nanoprecipitation technique in which $27 \mathrm{mg}$ of PLGA was dissolved in minimum amount of DMF ( $2 \mathrm{~mL}$ ) by vortexing. To this PLGA solution, cisplatin $(10.5 \mathrm{mg})$ was added. Then, this organic solution was added dropwise to of PVA $(20 \mathrm{~mL})$ earlier dissolved in DI water $(1 \% \mathrm{w} / \mathrm{v})$ and stirred for few minutes. The excess amount of PVA and DMF were removed by centrifugation at 10,000 rpm (Thermo Sorvall Legend X1R) for $30 \mathrm{~min}$ at $20^{\circ} \mathrm{C}$. The final pellet was dispersed in water $(8 \mathrm{~mL})$ followed by vortexing at $4^{\circ} \mathrm{C}$ and kept until apply within $1 \mathrm{~h}$ or lyophilized and stored for extended periods of time [31].

2.3. Fourier Transform Infrared (FTIR) Spectroscopy. The FTIR spectroscopy measurements were recorded to characterize the probable participation of the functional groups of cisplatin in synthesized PLGA-cisplatin. The FTIR spectra of PLGA-cisplatin NPs were acquired in an Avatar 330 FTIR spectrometer (Thermo Fisher Scientific, Waltham, MA, USA) over a scale of $4,250-500 \mathrm{~cm}^{-1}$ after adding with $\mathrm{KBr}$ pellets [32].

2.4. Atomic Force Microscopy (AFM). To observe the surface morphology and measure the size of the resultant PLGAcisplatin NPs, an AFM was applied. The sample was dropped onto newly cleaved mica slices and dried overnight. An AGILENT-N9445A series 5500 AFM (Agilent Technologies, Santa Clara, CA, USA), which was equipped with Pico View software, was used.

2.5. Cell Culture. The human embryonic kidney cells (HEK293) and breast cancer cell line (MCF-7) were achieved was acquired from ATCC, USA. These cells were culture in DMEM having $10 \%$ FBS with $1 \%$ antibiotic cocktail in a humidified medium under constant $5 \% \mathrm{CO}_{2}$ at $37^{\circ} \mathrm{C}$. Cell seeding was completed with EDTA $(0.52 \mathrm{mM})$ and trypsin $(0.25 \%)$ in phosphate-buffered saline (PBS) after $70-75 \%$ confluence. Later, the cells were plated at an essential concentration to allow them to reequilibrate before performing the experiment [33]. 


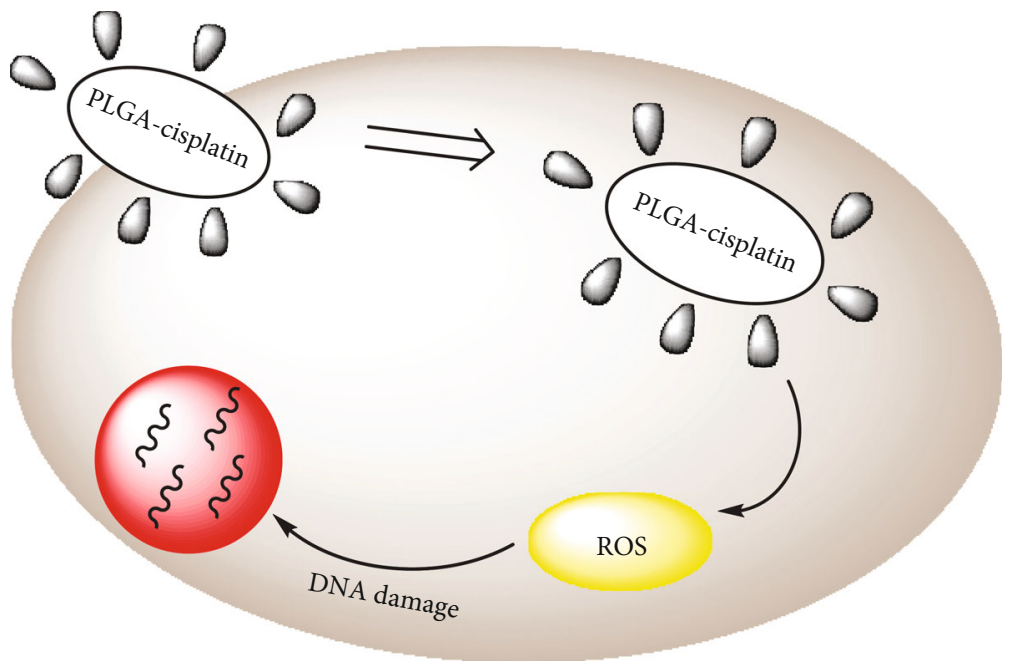

FIgURE 1: Schematic representation of encapsulation of PLGA-cisplatin NPs and their mode of action.

2.6. Determination of Cell Viability. Determination of cell viability was done by MTT [(4,5- dimethyl-thiazol-2-yl)2,5-diphenyl-tetrazolium bromide] assay [34]. HEK293 and MCF-7 cells were seeded at a required density $\left(4 \times 10^{3}\right.$ cells/well) in a 96-well plate from the respective plate. After 18 $-24 \mathrm{~h}$ of seeding, cells were treated with cisplatin and PLGA-cisplatin at $0-50(\mu \mathrm{g} / \mathrm{mL})$ followed by an initial screening for different time duration. After treatment, plates were placed for $24 \mathrm{~h}$ in an incubator at $37^{\circ} \mathrm{C}$ in a humidified $\mathrm{CO}_{2}$-rich condition (5\%). After incubation for $24 \mathrm{~h}$, cells were rinsed from each well of 96-well plates by PBS. Then, the MTT solution was added to each well and reserved in an incubator for $4 \mathrm{~h}$ to appear formazan dye. The formazan dye was then solubilized using DMSO, and the absorbance was taken at $595 \mathrm{~nm}$ using an ELISA reader (EMax, Molecular Device, USA) [35]. Cell propagation was evaluated from the absorption intensity in terms of cell viability as follows:

$$
\text { Cell viability }=\frac{\text { OD of Control }- \text { OD of treated }}{\text { OD of Control }} \times 100 \text {. }
$$

In each case, the PLGA-cisplatin was sonicated before considering in a cell line to obtain homogenized mixtures. Each experiment was repeated thrice to obtain reported biological results.

2.7. Detection of Apoptosis/Necrosis. Necrotic and apoptotic cell death was determined using the Annexin-V FITC/PI apoptosis detection kit (Calbiochem, CA, USA). The MCF7 cells were plated in six-well plates then treated with PLGA-cisplatin at $23 \mu \mathrm{g} / \mathrm{mL}$. After 12 and $24 \mathrm{~h}$ of incubation, the cells were washed and stained with propidium iodide (PI) and Annexin-V-FITC in the presence of binding buffer as per the manufacturer's protocols [36]. The early and late apoptotic percentages, live, and necrotic cells were analyzed using a flow cytometer (BD LSRFortessa ${ }^{\mathrm{TM}}$ San Jose, CA, USA). The acquired data were analyzed using FlowJo (version 10.0) software.

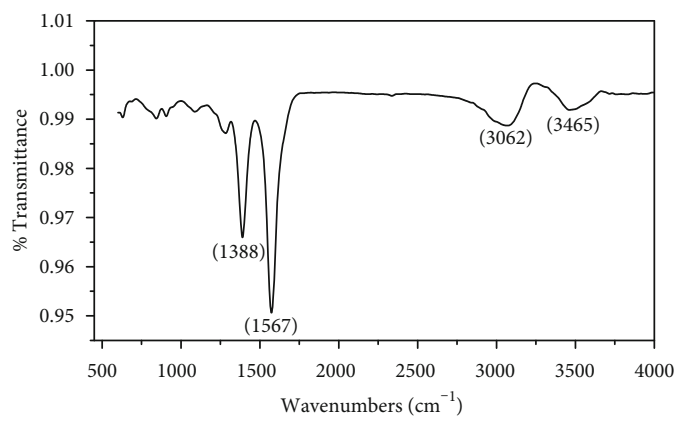

FIgUre 2: FTIR data of PLGA-cisplatin.

2.8. DNA Fragmentation Assay. Treated cells with the PLGAcisplatin nanoparticles at different concentrations (0-40 $\mu \mathrm{g} / \mathrm{mL}$ ) were analyzed for $24 \mathrm{~h}$. Then, the resultant fragmented DNA was calculated using commercially obtainable kits at $405 \mathrm{~nm}$ according to the manufacturer's procedure [37].

2.9. Assessment of Intracellular ROS. Intracellular mitochondrial ROS have been calculated following the previously reported protocols [38]. To adopt the intercellular ROS, we incubated the treated MCF-7 cells with $10 \mu \mathrm{M} 2^{\prime}, 7^{\prime}$ -dichlorofluorescein diacetate (DCF-DA) for $25 \mathrm{~min}$. The slides were then counterstained with DAPI for $10 \mathrm{~min}$ and mounted with the ProLong Antifade Reagent (Molecular Probe, Eugene, OR, USA). Later, the slides were subjected to confocal laser scanning microscope (FV 10i, Olympus, Japan) [39]. The change of DCF-DA fluorescence used as a fluorescent indicator of ROS formation in cell culture-based antioxidant assays.

2.10. In Vitro Cisplatin Release. The in vitro cisplatin release experiments were conducted at $\mathrm{pH} 5.5$ with $10 \mu \mathrm{g} / \mathrm{mL}$ of cisplatin containing PLGA. $1 \mathrm{~mL}$ of PLGA-cisplatin was loaded into a dialysis bag, then dispersed in a $50 \mathrm{~mL}$ of $\mathrm{PBS}$ of $\mathrm{pH} 7.4$ at $37^{\circ} \mathrm{C}$. Further, the full system was transferred at $130 \mathrm{rpm}$ 

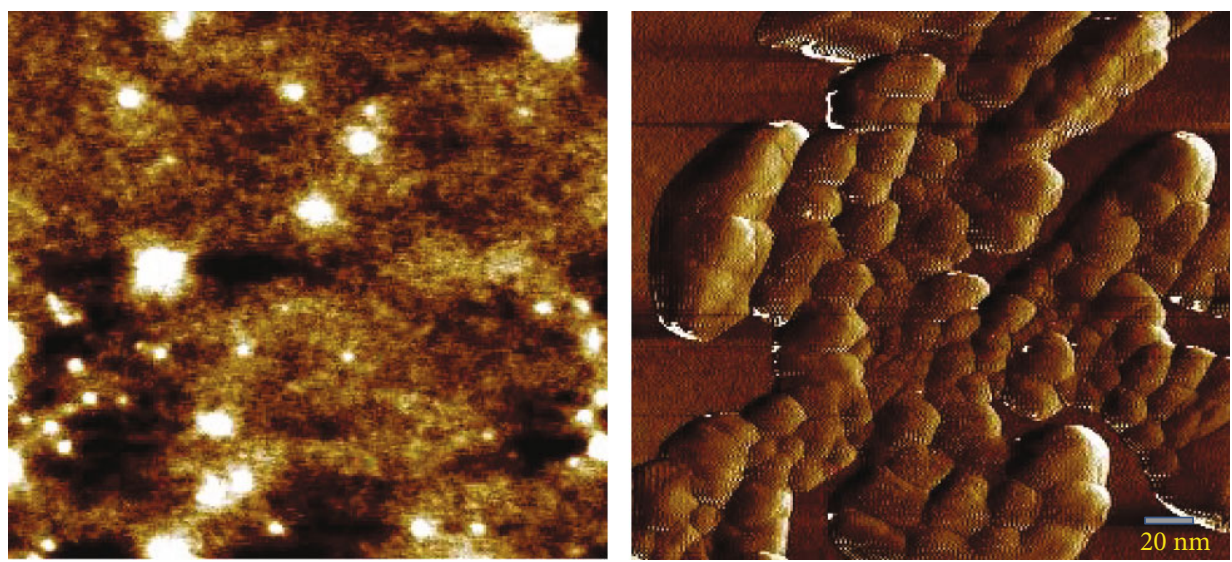

FIgure 3: AFM data of PLGA-cisplatin.

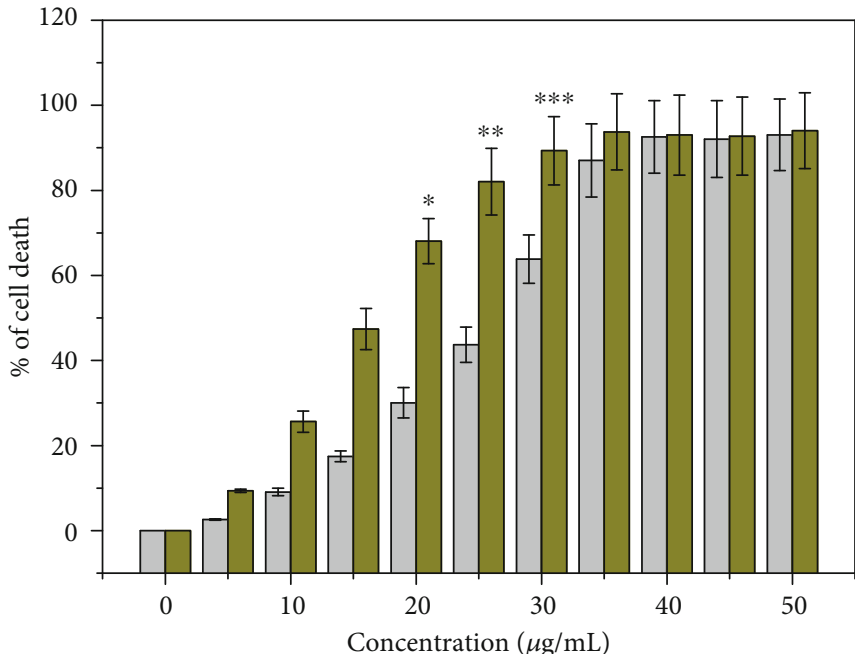

Cisplatin PLGA-cisplatin

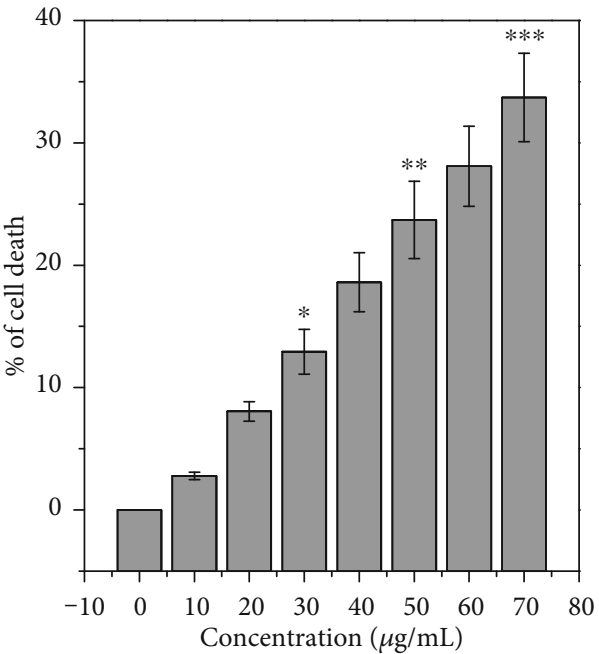

(b)

FIGURE 4: (a) Rate of cell death of MCF-7 cells after treatment with cisplatin only and PLGA-cisplatin for $24 \mathrm{~h}$ as evaluated by MTT assay. (b) Rate of cell death of HEK-293 cells after treatment with PLGA-cisplatin NPs. Each value represents the mean \pm SE of three experiments. $n=3$ $\left({ }^{*} p<0.05,{ }^{* *} p<0.01\right.$, and $\left.{ }^{* * *} p<0.001\right)$, compared with the control.

for $24 \mathrm{~h}$. From the above dispersions after $2 \mathrm{~h}$ intervals, 500 $\mu \mathrm{L}$ aliquots were drawn and it was replaced by an equal volume of the fresh PBS solution for retaining the same release medium. The released amount of cisplatin was determined spectrophotometrically at $510 \mathrm{~nm}[40]$.

2.11. Statistical Analysis. Data were represented as mean \pm SEM of the multiple data points. Statistical significance in the deference was calculated using analysis of variance (ANOVA) using OriginPro (version 8.0) software where $p$ $<0.05$ was considered significant.

\section{Result and Discussion}

3.1. Characterization of PLGA-Cisplatin NPs. The encapsulation of weakly soluble and toxic drugs within polymeric NPs increases their therapeutic and pharmacodynamics performance and decreases their side effects [41]. Cisplatin is poor soluble in water $(0.23 \mathrm{~g} / 100 \mathrm{~mL}$ of water) and organic solvents makes it quite difficult to prepare concentrated solutions necessary to produce NPs. Although DMSO is well known to be a good solvent for cisplatin, it has been reported to compromise the cytotoxic potency of the drug, so DMF was chosen as an organic solvent for the preparation of NPs.

The FTIR spectrum of the sample after the encapsulation of cisplatin is reported (Figure 2). Two peaks were found in the $3062-3465 \mathrm{~cm}^{-1}$ (related to asymmetric and symmetric stretching of $-\mathrm{NH}$ group) and $1600-1300 \mathrm{~cm}^{-1}$ (related to $\mathrm{HNH}$ asymmetric and symmetric bending). Some peaks were observed in between 500 and $1300 \mathrm{~cm}^{-1}$ (viz. at $956 \mathrm{~cm}^{-1}$ for $-\mathrm{OH}$ bending), which are the characteristic peaks of PLGA. 


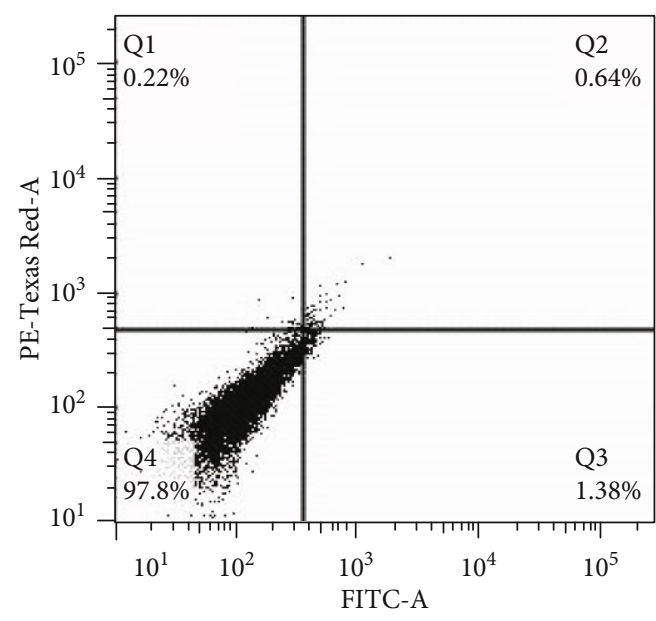

(a)

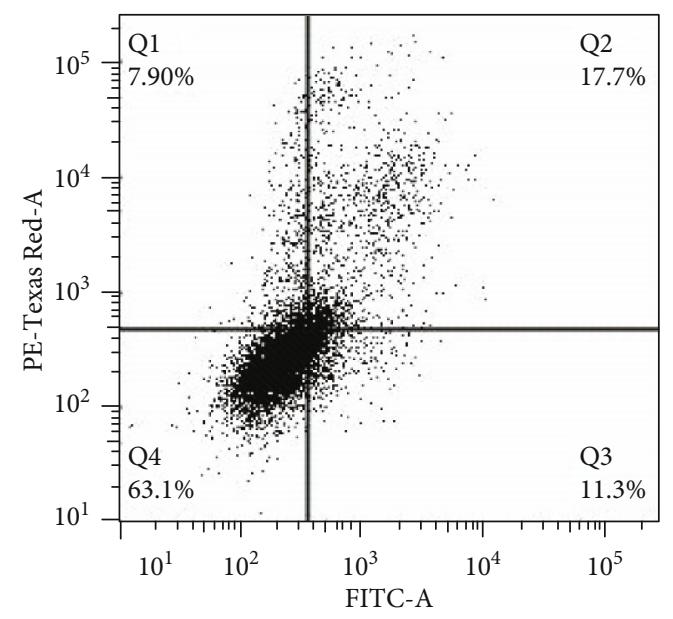

(b)

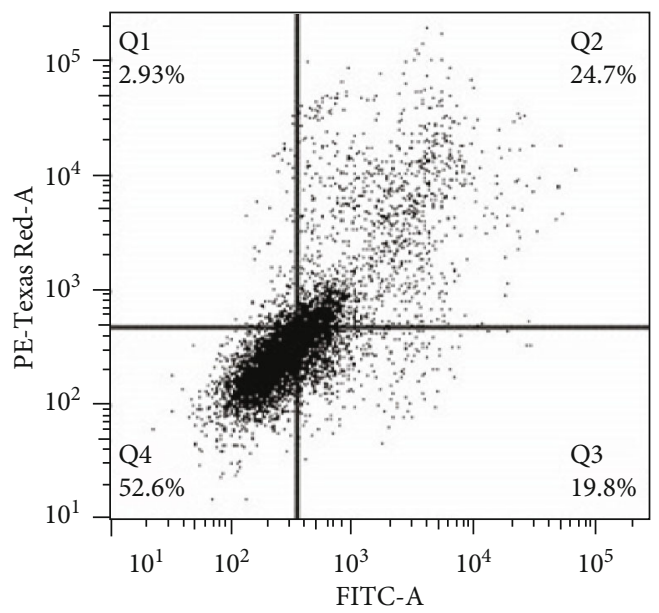

(c)

FIGURE 5: Annexin-V/PI staining to analyze apoptosis/necrosis in MCF-7 cells. Time-dependent study (12 and $24 \mathrm{~h})$ after treatment of cells with $23 \mu \mathrm{g} / \mathrm{mL}$ of PLGA-cisplatin. (a) Untreated cells. (b) Differences in the percentage of cell death in the treated cells for $12 \mathrm{~h}$. (c) Differences in the percentage of cell death in treated cells for $24 \mathrm{~h}$.

Then, we have studied the size and shape of the PLGAcisplatin NPs by AFM. The AFM data (Figure 3 ) suggest that PLGA-cisplatin exhibits nanosphere-like shape. We have calculated the size which is around $95.56 \pm 7.94 \mathrm{~nm}$ from the AFM images.

3.2. PLGA-Cisplatin NPs Induced Cytotoxicity. The cytotoxic effects of PLGA-cisplatin NPs have been tested against the breast cancer cell line (MCF-7) by MTT assay. Based on the values of $\mathrm{IC}_{50}$, different concentrations between 0 and 50 $\mu \mathrm{g} / \mathrm{mL}$ of PLGA-cisplatin NPs were selected and the treatment period was for a $24 \mathrm{~h}$ period. The MTT assay data cleared that the cell death has been increased with the concentration of PLGA-cisplatin NPs. We have also evaluated the cytotoxicity of cisplatin in the same concentration range. From the MTT assay, we have acquired the $\mathrm{IC}_{50}$ value of PLGA-cisplatin NPs is $23 \pm 2.80 \mu \mathrm{g} / \mathrm{mL}$, whereas in case of only cisplatin, the $\mathrm{IC}_{50}$ value is $38 \pm 3.78 \mu \mathrm{g} / \mathrm{mL}$. This MTT assay data cleared that PLGA-cisplatin NPs are superior cytotoxic than cisplatin only (Figure 4(a)). We have also checked the cytotoxicity of NPs in the HEK-293 cell line. The data concluded that, after $40 \mu \mathrm{g} / \mathrm{mL}$, significant cell death was found (Figure 4(b)).

3.3. PLGA-Cisplatin NPs Induced Apoptosis in MCF-7 Cells. To examine whether the PLGA-cisplatin nanosphere was involved in apoptosis/necrosis, flow cytometric assessment was performed using Annexin-V-FITC/PI staining by analyzing the elevated level of serine phosphatidyl in the outer membrane of cells. As shown in (Figure 5), it was evident that the percentages of apoptotic (early and late) cells have been enhanced in a time-dependent manner (11.3\% EA/17.7\% LA for $12 \mathrm{~h}$ and $19.8 \% \mathrm{EA} / 24.7 \%$ in LA for $24 \mathrm{~h}$ ) after treatment of $23 \mu \mathrm{g} / \mathrm{mL}$ of PLGA-cisplatin NPs, with respect to the control cells (1.38\% EA and $0.64 \% \mathrm{LA})$. These results suggested that PLGA-cisplatin NPs-induced cell death was directly correlated with cytotoxicity followed by apoptosis.

3.4. Assessment of Intracellular ROS Generation. Cisplatin is a well-known ROS inducer [42]. So, we have established the 

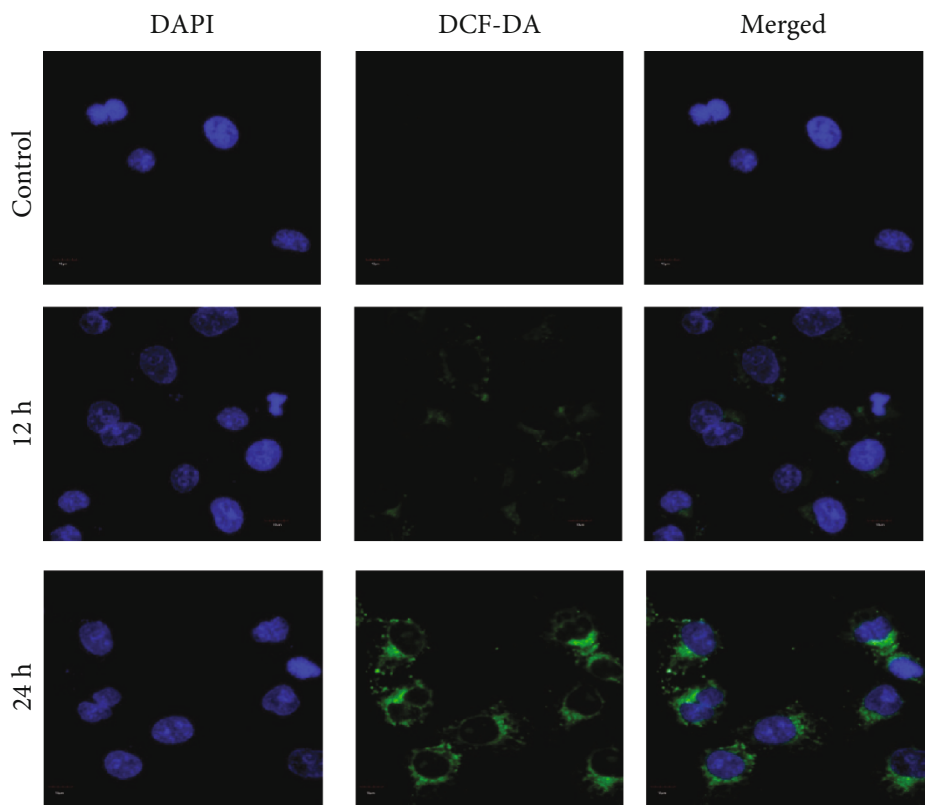

Figure 6: Measurement of ROS generation after a time-dependent treatment (12 and $24 \mathrm{~h}$ ) of $23 \mu \mathrm{g} / \mathrm{mL}$ PLGA-cisplatin (DAPI-nuclear stainer).

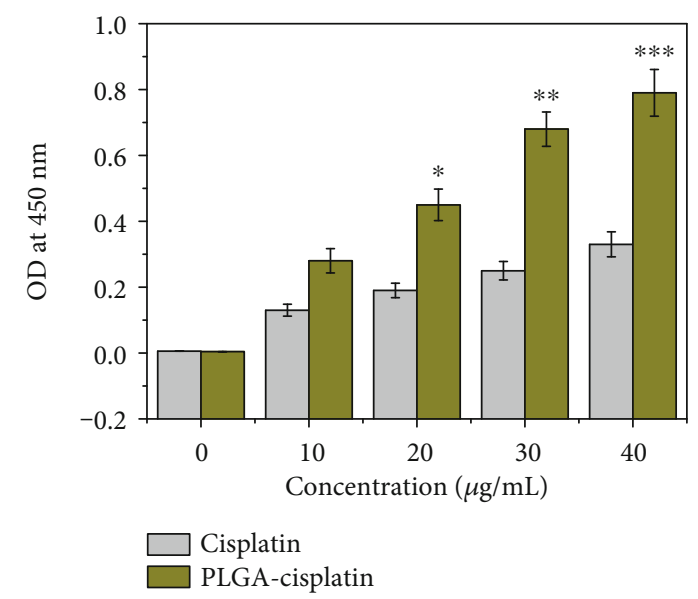

Figure 7: DNA fragmentation assay: cisplatin- and PLGAcisplatin- $(0-40 \mu \mathrm{g} / \mathrm{mL})$ treated MCF-7 cells. Each value represents the mean \pm SE of three experiments, $n=3\left({ }^{*} p<0.05,{ }^{* *} p<0.01\right.$, and $\left.{ }^{* * *} p<0.001\right)$, compared with control.

ROS generation by confocal microscopy after PLGAcisplatin NP treatment $(23 \mu \mathrm{g} / \mathrm{mL})$ in a time-dependent manner (12 and $24 \mathrm{~h}$ ) using the DCF-DA dye as an indicator of ROS. Increase in DCF-DA fluorescence emission (595 nm) is the indication of increase in ROS (Figure 6). Here, DAPI has been taken as a nuclear stainer. As shown in Figure 5, the microscopic images showed that the green emission has been increased in a time-dependent manner after treatment of $23 \mu \mathrm{g} / \mathrm{mL}$ of PLGA-cisplatin NPs. This above data confirmed that PLGA-cisplatin NPs are increasing ROS in theMCF-7 cell line.

3.5. Detection of DNA Damage. ROS overload also prompts oxidative damage to the cell's biomacromolecules, which cul-

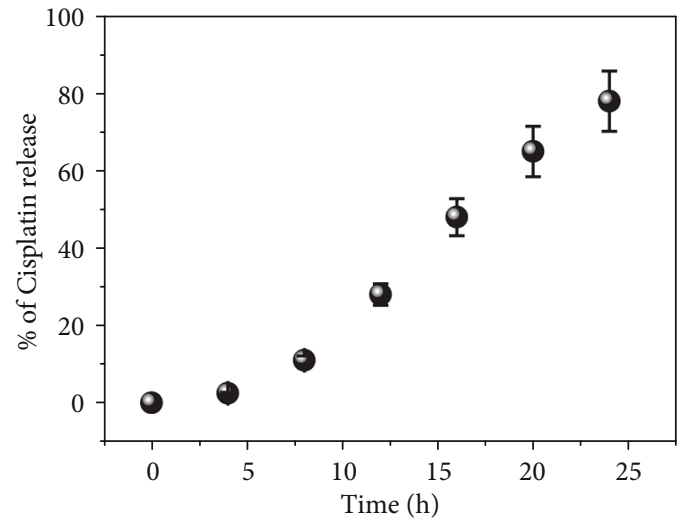

FIgURE 8: Time-dependent cisplatin release from PLGA-cisplatin at $\mathrm{pH}-5.5$ (UV-Vis spectroscopic data). Each value represents the mean \pm SE of three experiments $(n=3)$.

minates in the cell dysfunction and death. At high levels, ROS can lead to impaired physiological function through cellular damage of DNA. Hence, the DNA fragmentation assay was accomplished for both cisplatin and PLGA-cisplatin NPs, respectively, at $0-40 \mu \mathrm{g} / \mathrm{mL}$ concentrations. For the purpose, we have selected the OD value after treatment at $405 \mathrm{~nm}$ (Figure 7). The OD value suggests that the DNA fragmentation has been increased with the concentration of cisplatin and PLGA-cisplatin NPs. However, in case of PLGAcisplatin NPs, the DNA fragmentation was found to be higher. This observation cleared that the elevated amount of ROS is damaging the DNA. These data showed that ROS-mediated DNA damage is correlated with PLGAcisplatin NP-induced apoptosis in MCF-7 cancer cells.

3.6. Drug Release of Cisplatin from PLGA-Cisplatin NPs. We have also checked the delivery of cisplatin from PLGA- 
cisplatin NPs at buffer of $\mathrm{pH}-5.5$ by dialysis membrane technique. The measured the OD value at $4 \mathrm{~h}$ interval and extended up to further $24 \mathrm{~h}$. It has been perceived that after $16 \mathrm{~h}$ almost $50 \%$ of cisplatin has been released, which confirmed that the bioavailability of PLGA-cisplatin NPs is more superior than only cisplatin (Figure 8).

\section{Conclusions}

In this study, cisplatin-loaded PLGA NPs possessing chemotherapy properties were obtained by a multistep process. PLGA-cisplatin NPs were characterized by AFM and FTIR techniques. The cytotoxicity data of the nanoparticles along with only cisplatin into MCF-7 have been evaluated by MTT Assay. A colorimetric UV-Vis method was adapted to quantify cisplatin in buffer samples. The $\mathrm{pH}$-dependent drug release profile of NPs was observed on the surrounding medium, favoring the release of cisplatin under an acidic environment. In this way, we confirmed that the bioavailability of PLGA-cisplatin NPs has been increased. As in case of PLGA-cisplatin, the anticancer efficacy is higher compared to only cisplatin, so the risk of severe physiological disorders will be reduced. We have also established that the ROS generation into MCF-7 has been increased after PLGAcisplatin nanoparticle treatment in a time-dependent manner. After that, we have checked the DNA damage which is following ROS generation data so we can say ROS generation is the cause of DNA damage in PLGA-cisplatin-induced apoptosis. Thus, PLGA-cisplatin NPs has huge potential to be employed as an anticancer agent to overcome the epidemiology of cancer in future.

\section{Abbreviations}

PLGA: Poly lactic-co-glycolic acid

BC: $\quad$ Breast cancer

ROS: $\quad$ Reactive oxygen species

ER: $\quad$ Estrogen receptor

PR: $\quad$ Progesterone receptor;

HER2: Human epidermal growth factor receptor

DMF: Dimethylformamide

PVA: Polyvinyl alcohol

OPDA: Orthophenylenediamine

OD: Optical density

MES: $\quad$ Ethanesulphonic acid clorhydrate

FTIR: $\quad$ Fourier transforms infrared

AFM: $\quad$ Atomic force microscopy

PSN: $\quad$ Penicillin-streptomycin-neomycin

DCF-DA: $2^{\prime}, 7^{\prime}$-Dichlorofluorescein diacetate.

\section{Data Availability}

The data generated or analyzed in this article are publicly available online without request.

\section{Conflicts of Interest}

The authors have declared that no competing interest exists.

\section{Authors' Contributions}

Mohammed Al-Zharani, Gadah Albasher, and Hani Alothaid performed cell culture and treatments. Norah Saad AL-Johani evaluated the cytotoxicity. Nada H. Aljarba, Mohammed H. Almarzoug, and Norah M. Alhoshani detected the apoptosis and necrosis. Mohammed AlZharani and Abdullah A. Alkahtane determined the oxidative stress and performed statistical analysis. Saad Alkahtani and Saud Alarifi were involved in the conception and design of the study, data interpretation, and critical revision of the manuscript. All authors read and approved the final manuscript.

\section{Acknowledgments}

The authors extend their appreciation to the Deanship of Scientific Research at King Saud University for funding this work through research group no (RG-1441-018).

\section{References}

[1] J. Ferlay, M. Colombet, I. Soerjomataram et al., "Estimating the global cancer incidence and mortality in 2018: GLOBOCAN sources and methods," International Journal of Cancer, vol. 144, no. 8, pp. 1941-1953, 2019.

[2] H. Brody, "Cancer prevention," Nature, vol. 471, no. 7339, p. S1, 2011.

[3] T. A. Gaziano, A. Bitton, S. Anand, S. Abrahams-Gessel, and A. Murphy, "Growing epidemic of coronary heart disease in low- and middle-income countries," Current Problems in Cardiology, vol. 35, no. 2, pp. 72-115, 2010.

[4] P. Anand, A. B. Kunnumakara, C. Sundaram et al., "Cancer is a preventable disease that requires major lifestyle changes," Pharmaceutical Research, vol. 25, no. 9, pp. 2097-2116, 2008.

[5] B. Han, L. Sha, X. Yu, M. Yang, Y. Cao, and J. Zhao, "Identification of dual therapeutic targets assisted by _in situ_automatous DNA assembly for combined therapy in breast cancer," Biosensors and Bioelectronics, vol. 176, article 112913, 2021.

[6] X. Wang, Y. Shi, D. Huang, and X. Guan, "Emerging therapeutic modalities of PARP inhibitors in breast cancer," Cancer Treatment Reviews, vol. 68, pp. 62-68, 2018.

[7] S. Al-Othman, A. Haoudi, S. Alhomoud, A. Alkhenizan, T. Khoja, and A. Al-Zahrani, "Tackling cancer control in the Gulf Cooperation Council Countries," The Lancet Oncology, vol. 16, no. 5, pp. e246-e257, 2015.

[8] B. Cánovas, A. Igea, A. A. Sartori et al., "Targeting p38 $\alpha$ Increases DNA Damage, Chromosome Instability, and the Anti- tumoral Response to Taxanes in Breast Cancer Cells," Cancer Cell, vol. 33, no. 6, pp. 1094-1110.e8, 2018.

[9] S. Modi, C. Saura, C. Henderson et al., "A multicenter trial evaluating retaspimycin HCL (IPI-504) plus trastuzumab in patients with advanced or metastatic HER2-positive breast cancer," Breast Cancer Research and Treatment, vol. 139, no. 1, pp. 107-113, 2013.

[10] S. Al-Bahlani, B. Al-Dhahli, K. Al-Adawi, A. Al-Nabhani, and M. Al-Kindi, "Platinum-based drugs differentially affect the ultrastructure of breast cancer cell types," BioMed Research International, vol. 2017, Article ID 3178794, 13 pages, 2017.

[11] A. Sartaj, S. Baboota, and J. Ali, "Exploring the therapeutic potential of nanostructured lipid carrier approaches to 
tackling the inherent lacuna of chemotherapeutics and herbal drugs against breast cancer," Journal of Drug Delivery Science and Technology, vol. 63, article 102451, 2021.

[12] T. Sorlie, C. M. Perou, R. Tibshirani et al., "Gene expression patterns of breast carcinomas distinguish tumor subclasses with clinical implications," Proceedings of the National Academy of Sciences of the United States of America, vol. 98, no. 19, pp. 10869-10874, 2001.

[13] G. Turashvili and E. Brogi, "Tumor heterogeneity in breast cancer," Frontiers in Medicine, vol. 4, 2017.

[14] P. ter Brugge, P. Kristel, E. van der Burg et al., "Mechanisms of therapy resistance in patient-derived xenograft models of BRCA1-deficient breast cancer," Journal of the National Cancer Institute, vol. 108, no. 11, article djw148, 2016.

[15] D. P. Silver, A. L. Richardson, A. C. Eklund et al., "Efficacy of neoadjuvant cisplatin in triple-negative breast cancer," Journal of Clinical Oncology, vol. 28, no. 7, pp. 1145-1153, 2010.

[16] M. P. Decatris, S. Sundar, and K. J. O’Byrne, "Platinum-based chemotherapy in metastatic breast cancer: current status," Cancer Treatment Reviews, vol. 30, no. 1, pp. 53-81, 2004.

[17] A.-M. Florea and D. Büsselberg, "Cisplatin as an anti-tumor drug: cellular mechanisms of activity, drug resistance and induced side effects," Cancers, vol. 3, no. 1, pp. 1351-1371, 2011.

[18] Z. H. Siddik, "Cisplatin: mode of cytotoxic action and molecular basis of resistance," Oncogene, vol. 22, no. 47, pp. 72657279, 2003.

[19] L. R. Kelland, "Preclinical perspectives on platinum resistance," Drugs, vol. 59, Supplement 4, pp. 1-8, 2000.

[20] J. Reedijk, "New clues for platinum antitumor chemistry: kinetically controlled metal binding to DNA," Proceedings of the National Academy of Sciences of the United States of America, vol. 100, no. 7, pp. 3611-3616, 2003.

[21] M. Konishi, Y. Tabata, M. Kariya et al., "In vivo anti-tumor effect through the controlled release of cisplatin from biodegradable gelatin hydrogel," Journal of Controlled Release, vol. 92, no. 3, pp. 301-313, 2003.

[22] S. Rezvantalab, N. I. Drude, M. K. Moraveji et al., "PLGAbased nanoparticles in cancer treatment," Frontiers in Pharmacology, vol. 9, p. 1260, 2018.

[23] W. Zhang, J. Shen, H. Su et al., "Co-delivery of cisplatin prodrug and chlorin e6 by mesoporous silica nanoparticles for chemo-photodynamic combination therapy to combat drug resistance," ACS Applied Materials \& Interfaces, vol. 8, no. 21, pp. 13332-13340, 2016.

[24] P. Dana, S. Bunthot, K. Suktham et al., "Active targeting liposome-PLGA composite for cisplatin delivery against cervical cancer," Colloids and Surfaces B: Biointerfaces, vol. 196, article 111270, 2020.

[25] V. V. Ranade, M. A. Hollinger, and J. B. Cannon, Drug Delivery Systems, CRC Press, 1995.

[26] G. Prencipe, S. M. Tabakman, K. Welsher et al., "PEG branched polymer for functionalization of nanomaterials with ultralong blood circulation," Journal of the American Chemical Society, vol. 131, no. 13, pp. 4783-4787, 2009.

[27] R. Mout, D. F. Moyano, S. Rana, and V. M. Rotello, "Surface functionalization of nanoparticles for nanomedicine," Chemical Society Reviews, vol. 41, no. 7, pp. 2539-2544, 2012.

[28] H. K. Makadia and S. J. Siegel, "Poly lactic-co-glycolic acid (PLGA) as biodegradable controlled drug delivery carrier," Polymers, vol. 3, no. 3, pp. 1377-1397, 2011.
[29] J. A. Loureiro and M. C. Pereira, "PLGA based drug carrier and pharmaceutical applications: the most recent advances," Pharmaceutics, vol. 12, no. 9, p. 903, 2020.

[30] R. Domínguez-Ríos, D. R. Sánchez-Ramírez, K. Ruiz-Saray et al., "Cisplatin-loaded PLGA nanoparticles for HER2 targeted ovarian cancer therapy," Colloids and Surfaces B: Biointerfaces, vol. 178, pp. 199-207, 2019.

[31] D. Moreno, S. Zalba, I. Navarro, C. Tros de Ilarduya, and M. J. Garrido, "Pharmacodynamics of cisplatin-loaded PLGA nanoparticles administered to tumor- bearing mice," European Journal of Pharmaceutics and Biopharmaceutics, vol. 74, no. 2, pp. 265-274, 2010.

[32] G. M. Severini, L. Pascolo, B. Bortot et al., "Detection of PLGAbased nanoparticles at a single-cell level by synchrotron radiation FTIR spectromicroscopy and correlation with X-ray fluorescence microscopy," International Journal of Nanomedicine, vol. 9, pp. 2791-2801, 2014.

[33] P. K. Das, F. Islam, and A. K. Lam, “The roles of cancer stem cells and therapy resistance in colorectal carcinoma," Cells, vol. 9, no. 6, p. 1392, 2020.

[34] C. Pathak, F. U. Vaidya, and S. M. Pandey, "Mechanism for development of nanobased drug delivery system," Applications of Targeted Nano Drugs and Delivery Systems, pp. 35-67, 2019.

[35] A. V. Tonder, A. M. Joubert, and A. D. Cromarty, "Limitations of the 3-(4, 5-dimethylthiazol-2-yl)-2, 5-diphenyl-2H-tetrazolium bromide (MTT) assay when compared to three commonly used cell enumeration assays," BMC Research Notes, vol. 8, pp. 1-10, 2015.

[36] P. C. Wever, J. Aten, R. J. Rentenaar et al., "Apoptotic tubular cell death during acute renal allograft rejection," Clinical Nephrology, vol. 49, no. 1, pp. 28-34, 1998.

[37] P. Bhanja, S. Mishra, K. Manna, A. Mallick, K. Das Saha, and A. Bhaumik, "Covalent organic framework material bearing phloroglucinol building units as a potent anticancer agent," ACS Applied Materials \& Interfaces, vol. 9, no. 37, pp. 31411-31423, 2017.

[38] B. Perillo, M. D. Donato, A. Pezone et al., "ROS in cancer therapy: the bright side of the moon," Experimental \& Molecular Medicine, vol. 52, no. 2, pp. 192-203, 2020.

[39] R. Nandi, S. Mishra, T. K. Maji et al., "A novel nanohybrid for cancer theranostics: folate sensitized $\mathrm{Fe}_{2} \mathrm{O}_{3}$ nanoparticles for colorectal cancer diagnosis and photodynamic therapy," Journal of Materials Chemistry B, vol. 5, no. 21, pp. 3927-3939, 2017.

[40] N. Deirram, C. Zhang, S. S. Kermaniyan, A. P. R. Johnston, and G. K. Such, "pH-responsive polymer nanoparticles for drug delivery," Macromolecular Rapid Communications, vol. 40, no. 10, article 1800917, 2019.

[41] N. Kamaly, B. Yameen, J. Wu, and O. C. Farokhzad, "Degradable controlled-release polymers and polymeric nanoparticles: mechanisms of controlling drug release," Chemical Reviews, vol. 116, no. 4, pp. 2602-2663, 2016.

[42] R. Marullo, E. Werner, N. Degtyareva et al., "Cisplatin induces a mitochondrial-ROS response that contributes to cytotoxicity depending on mitochondrial redox status and bioenergetic functions," PLoS One, vol. 8, no. 11, article e81162, 2013. 